\title{
TEACHING OF ACOUSTICS
}

A DISCUSSION on the teaching of acoustics, under the joint auspices of the Acoustics Group of the Physical Society and the Education Group of the Institute of Physics, was held at the offices of the Institute in London on November 19, 1952, Mr. W. West, chairman of the former Group, presiding. Dr. R. W. B. Stephens, in introducing the subject, said that acoustics has for long been somewhat neglected in schools and universities of Great Britain. 'This state of affairs is unfortunate ; for the study of vibrations is fundamental to the whole of physics, and acoustics is probably the best vehicle for illustrating wave motion, as it provides a means of actually observing the nature of the motion as distinct from inferring it-for example, as in the case of light. In schools, a reason for the somewhat scanty attention to the subject most probably arises from the very crowded syllabus and from the fact that, viewed from the aspect of passing the General Certificate Examination (ordinary level), it has a limited value. It has been the practice for some time for only one or two questions to be set, and these in general have been modifications on a very restricted theme, which must have brought about a tendency to limit the teaching of the subject to the consideration of the few types of questions which are likely to occur. It is evident, thought Dr. Stephens, that examiners cannot escape criticism, for in the wording of questions more attention might be directed to the physics of a problem rather than making it a problem in algebra and a substitution in a formula.

In college and university there is the tendency to restrict the teaching of acoustics and regard it perhaps somewhat as an applied subject which by modern standards puts it on a lower academic plane, compared with theoretical nuclear physics. In point of fact, however, modern acoustical theory uses all the tools of mathematical physics. The treatment of acoustics as a Cinderella subject is somewhat unfortunate, as apart from academic considerations (and these are widespread, for basic acoustic theory and techniques permeate into the fields of aeronautics, applied mechanics, light electrical engineering, rheology, etc.) there is also the impact of the subject on modern everyday life which is made increasingly evident-to mention a few examples - by the problems arising from noise and vibration in aircraft, flats, factories, etc. ; design of concert halls ; development of electronic musical instruments, etc.

Dr. Stephens then gave the results of a questionnaire on this subject circulated to universities by the Acoustics Group. It appears that most universities think that a course is desirable, and most do give their students a specialized course of ten to fifteen lectures. There are seven postgraduate courses in all, and a number have facilities for research.

Mr. E. Nightingale, as a schoolmaster of long experience, admitted that in schools the subject does not receive anything like the attention it deserves. This is due partly to the greatly expanding physics syllabus, and partly to the fact that many teachers are afraid of the subjoct unless they are musically minded. Also, one must face the fact that, in the early stages, the subject does not lend itself to practical work mainly owing to the necessity for quiet in many of the experiments. This leads to the complete exclusion of the subject at this stage and to an inadequate and sketchy treatment in the sixth form. In the old days, when 'heat, light and sound' was an examination subject for the School Certificate, acoustics received far more adequate treatment than at present.

'The teaching of acoustics, continued Mr. Nightingale, can be begun informally quite early by means of a useful talk on the meaning of frequency, overtone and harmonic, illustrated by simple experiments on the piano and the violin or 'cello. There is also great scope for a series of formal lessons illustrated by simple experiments of the 'sealing wax and string' type. These can give a far better training in basic physics than any number of spectacular experiments using boxed-up apparatus of the push-button type. The mathomatical theory of wave motion must be left largely to the sixth form, when the necessary mathematical equipment should be available. But the fundamental ideas of frequency, period, wavelength, the equation $V=n \lambda$, the simple treatment of resonance and beats, the dependence of quality on overtones, can all be taught in the pre-Certificate course.

Mr. Nightingale then illustrated some simple experiments within the capabilities of a secondary school and showed -on a tape record - what could be done on a piano.

Dr. E. G. Richardson pointed out that acoustics is now firmly established as a subject for special study and research in four British universities, mainly with the aid of the University Grants Committee and of certain government institutions, which are anxious to have available personnel trained in the subject. Though this is good so far as it goes, the facilities in acoustics compare unfavourably with some other countries. In both the United States and Germany there are university departments or whole institutes devoted to this subject. (In the United States a number are called applied physics, but they are really acoustics plus electronics or radio waves, and the same combinations are found in Germany.) In some other European countries there are acoustics departments attached usually to technological universities, but in other countries acoustical work is done in government institutes with but a slendor attachment or none to a university faculty.

Four types of students in universities require instruction in sound. Physicists certainly do, but more restricted courses are also given to architects, electrical engineers and musicians. Until he gets into the special honours school, the physics student gets little sound, but in fifteen lectures enough can be done to prepare the student for a post in industry or to start postgraduate research. There is no doubt, said Dr. Richardson, that nowadays a student could scarcely undertake experimental research in sound without a good working knowledge of electronics. In the days of Rayleigh and Lamb, hydrodynamics was the handmaid of acoustics. The pendulum has swung too far in the direction of making acoustics a branch of radio communication, which Dr. Richardson thinks is undesirable except for electrical engineers.

In the general discussion that followed, Mr. W. A. Mercer gave details of courses he is giving to honours physicists in the University of Southampton; he divides the subject into classical and modern acoustics, devoting more time to the latter. Drs. H. 
Lowry and W. H. George spoke of the difficulties of teaching sound to music students, and the latter spoke also of the new M.Sc. course in the University of London, while Mr. S. R. Humby amplified previous speakers' comments on the teaching of wave motion to sixth-form schoolboys. At the conclusion of the discussion, experiments suitable for demonstrations were inspected.

\section{PHYSIOLOGY OF THE HOST- PARASITE RELATIONSHIP IN FUNGI AND BACTERIA}

$\mathrm{T}$

HE annual plant-pathological meeting of the British Mycological Society, which was held on October 17 in the Physics Lecture Theatre of Birkbeck College, London, took the form of a symposium on the physiological relationship of host plant and parasite. Nine papers were read dealing with various aspects of this wide problem.

Prof. W. Brown (Imperial College of Science and Technology, London), who introduced the discussion, dealt primarily with the type of facultative parasite which is relatively non-specialized and which characteristically brings about a distinct rotting and killing of the host tissue. This is probably the simplest of all types and the one most open to investigation, as the effects arising are localized to the neighbourhood of the parasite and can, to a large extent, be reproduced in vitro. It is logical, therefore, to begin by attempting to elucidate the mechanism of the more generalized parasites and to proceed from there to the more specialized types, as illustrated by the obligate but also by many facultative parasites.

Events which take place before the parasite has penetrated the outer wall of the host and the act of penetration itself are of considerable interest and practical importance, and the physiology of these stages could be further clarified. It is, however, when entry has taken place that the most interesting relationships develop. The tissue-destroying agents are metabolites excreted by the parasites, and, though it is not safe to ignore any of these, chief attention has been paid to pectolytic enzymes and organic acids. With some fungi, such as Botrytis cinerea, pectin-dissolving enzymes appear to be the sole agents. The study of this parasite and of others which act similarly, for example, Pythium spp., Bacterium aroidece, has thus become largely enzymological, with special reference to the conditions which govern enzyme secretion, and to the detailed differences in behaviour (such as selective action on various cell walls and constituents of cell walls, relation to $p \mathrm{H}$. and to various retarding and inhibiting agents, etc.) which are shown by the pectolytic enzyme systems of various parasites and saprophytes.

The part played by contact stimulation (thigmotropism) in the physiology of obligate parasites was discussed by Dr. S. Dickinson (Cambridge). It has been shown that the latter (rusts, powdery and downy mildews) respond to a contact stimulus by division of their nuclei, such stimulation being given on contact with stomatal guard cells, cuticle of epidermis, mesophyll wall and perhaps even outer layer of the protoplast. Thigmotropism is therefore a primary factor in obligate parasitism, a view which accords with recent American work in this field. It is suggested that this particular response to contact stimulation is the chief distinguishing characteristic between obligate and facultative parasites, and that in other ways, for example nutrition, they do not materially differ.

Dr. S. E. Jacobs and Mr. A. H. Dadd (Imperial College of Science and Technology, London), dealing with the leafy-gall organism (Corynebacterium fascians) and its behaviour on a wide range of host plants, showed that diffusible antibiotic substances are present in seeds of some of these host species. An inverse relation was discovered between percentage of seedling infection and the degree of inhibition of the bacterium brought about by exudates from seed. The inhibitory substance, when present, could be removed by soaking the seeds, but this treatment did not lead to increased infection; it had the reverse effect, possibly because of simultaneous removal of diffusible nutrients. Extracts of crushed seeds, especially after being allowed to undergo a certain amount of bacterial decomposition, stimulated growth of the parasite and increased the pathogenicity of all pathogenic strains, but failed to stimulate nonpathogenic strains to attack the host. These effects were likewise obtained by use of various chemical substances.

Mr. J. E. Crosse (East Malling Research Station) outlined the annual cycle of the bacteria] canker disease of cherry caused by Pseudomonas morsprunorum, an over-wintering canker phase on the bark alternating with an over-summering leaf-spot phase. Infections of the bark take place in the autumn and mainly through the scar-wounds which arise at leaf-fall. Experiments with concentrated inocula gave a much higher percentage infection of a resistant as compared with a susceptible variety than was normally encountered in the field. This disparity was traced to the fact that in the autumn the parasite was more abundant on the leaves of the susceptible than of the resistant variety. As the infective bacteria are washed down by rain, the concentration of inoculum in the infection drops is likely to be higher in the susceptible variety.

A series of inoculation experiments, carried out with a range of concentrations of inoculum and at four dates during the leaf-fall period, showed clearly that the concentration of inoculum necessary to give 50 per cent infection was higher with the resistant variety. Resistance to canker under field conditions was thus a compound of two factors, a lower prevalence of the parasite on the leaf surface and a higher threshold concentration of inoculum required for infection. As a result, the conditions necessary for successful invasion were less often realized at ports of entry on the resistant variety. Infectivity of leaf scars had also been shown to vary with the date at which inoculum was applied; but the precise relationship had not yet been worked out.

Dr. P. S. Nutman (Rothamsted Experimental Station) discussed the interaction between leguminous plants, in particular clover, and strains of the noduleforming organism. 'Effective' or symbiotic strains produced a limited number of nodules which were large and which fixed nitrogen; 'ineffective' or parasitic strains gave nodules in abundance, but these remained small because of early degeneration of their growing-points and they did not fix nitrogen. Incompatibility between the clover plant and $a$ bacterial strain which was normally effective was also shown in certain nutritive states of the former, and the same appearances resulted as with an 